ISSN: 0212-0267

DOI: http: //dx.doi.org/Io.I420I/hedu20I9383957

\title{
EL JUEGO POPULAR Y TRADICIONAL EN LA HISTORIA DE LA EDUCACIÓN ESPAÑOLA CONTEMPORÁNEA
}

\section{The popular and traditional play in the history of contemporary Spanish education}

\author{
Andrés PAYÀ RICO \\ Universidad de Valencia \\ Correo-e: andres.paya@uv.es
} Recepción: I9 de octubre de 20I8. Envío a informantes: 25 de octubre de 2018
Aceptación definitiva: ro de diciembre de 2018

REsumen: Los juegos populares y tradicionales forman parte de la identidad cultural y del patrimonio inmaterial de una sociedad. Como tal, con el paso de los tiempos, estos han sido transmitidos y conocidos por las diferentes generaciones que han podido aprender los distintos códigos culturales y socializarse jugando los mismos juegos que sus antepasados. Así pues, podemos afirmar que estos juegos son parte del currículo que las sociedades han legado a los más jóvenes. En el presente artículo realizaremos un recorrido por las principales reivindicaciones y usos que los discursos pedagógicos en España han ido realizando en torno al juego popular y tradicional como elemento educativo.

Palabras clave: juegos populares; juegos tradicionales; cultura; historia de la educación; patrimonio educativo.

Aвstract: Popular and traditional play is part of the cultural identity and intangible heritage of a society. As such, with the passage of time, these have been transmitted and known by different generations who have been able to learn the different cultural codes and socialize playing the same games as their ancestors. Thus, we can affirm that these games are part of the curriculum that societies have bequeathed to the youngest. In this article we will make a tour of the main claims and uses that the pedagogical discourses in Spain have been doing around the popular and traditional play as an educational element. 
KEY WORDs: popular play; traditional play; culture; history of education; educational heritage.

\section{El juego en la pedagogía contemporánea española}

$\mathrm{E}$

L JUEGO ES UNA DE LAS ACTIVIDADES PRINCIPALES DE LA INFANCIA y, como tal, ocupa (o debería ocupar) gran parte del tiempo que los más pequeños dedican en su cotidianeidad diaria. Como ya indicó en $1938^{1}$ el clásico estudio del historiador y filósofo holandés Johan Huizinga, somos Homo ludens, señalando de este modo la importancia del juego en el desarrollo humano, siendo así el acto de jugar consustancial a la cultura humana o, lo que es lo mismo, el «elemento de juego en la cultura» y «no el elemento de juego de la cultura». Siendo esto cierto, se hace difícil, si no imposible, comprender el acto educativo y el desarrollo cultural sin atender a la actividad lúdica. Aunque, como veremos en el presente estudio, a lo largo de nuestra historia contemporánea, un buen número de educadores y educadoras han prestado atención en sus escritos, debates pedagógicos, prácticas formativas y teorías al juego, sin embargo, sorprendentemente, desde la historia de la educación española, apenas se había prestado atención al mismo como objeto de estudio. Afortunadamente, en la última década esta situación se ha revertido ${ }^{2}$, apareciendo entre nuestra comunidad científica varios

Huizinga, Johan: Homo ludens, trad. de Eugenio Ímaz, Madrid, Revista de Occidente, 1938. Sin ánimo de ser exhaustivos, cabe citar aquí, entre otros, los estudios de Xavier Torrebadella i Flix y de Jordi Brasó i Rius desde la historia de la educación física, el deporte y el folklore [Torrebadella, Xavier: «Vicente Naharro y los juegos corporales en la Educación Física española de la primera mitad del siglo XIX», Ágora para la Educación Física y el Deporte, vol. 13, 2 (20II), pp. I65-I8I; Brasó, Jordi y Torrebadella, Xavier: «El joc del rescat a Catalunya. Un projecte educatiu a l'Escola del Mar de Pere Vergés», Temps d'educació, 47 (20I4), pp. I9I-2I2; Brasó, Jordi y Torrebadella, Xavier: «Anàlisi i classificació dels jocs de la infància de Joan Amades en funció de la seva lògica interna $i$ del gènere dels practicants (I674-1947)", REIRE: revista d'innovació $i$ recerca en educació, vol. 8, 2 (20I5), pp. I8-42; Brasó, Jordi y Torrebadella, Xavier: «"El marro", un juego tradicional y popular en la educación física española (I807-I936)», Revista Complutense de Educación, vol. 26, 3 (2015), pp. 697-719; Brasó, Jordi y Torrebadella, Xavier: «El joc del "rescat" en el procés constituent de l'esport contemporani a Catalunya (1900-1926)", Aloma: revista de psicologia, ciències de l'educació $i$ de l'esport, vol. 33, I (2015), pp. 79-92; Brasó, Jordi y Torrebadella, Xavier: «El juego motor del marro: una indagación acerca de sus raíces pedagógicas», Revista de Dialectología y Tradiciones Populares, tomo 72, Cuaderno I (enero-junio 20I7), pp. 245-264; Brasó, Jordi: «Pere Vergés: escuela y gamificación a comienzos del s. xx», Apunts: Educación física y deportes, 133 (2018), pp. 20-37; BRAsó, Jordi y Collell, Xevi: «El joc popular de la xarranca. Estudi a través dels llibres i del folklore català. Possibles aplicacions en l'àmbit escolar», REIRE: revista d'innovació i recerca en educació, vol. 9, 2 (20I6), pp. 82-IO5; BRAsó, Jordi y Torrebadella, Xavier: «Anàlisi i classificació dels jocs de la infància de Joan Amades en funció de la seva lògica interna i del gènere dels practicants (1674-I947)», REIRE: revista d'innovació $i$ recerca en educació, vol. 8, 2 (2015), pp. I8-42; Brasó, Jordi: «Thomas Arnold, Pere Vergés i els jocs organitzats. Els escacs, un projecte educatiu a l'Escola del Mar», Temps d'educació, 49 (2015), pp. 135-I63; Brasó, Jordi: El joc, un element clau en la bistòria de la renovació pedagógica, tesis doctoral. Universitat de Barcelona, 20I7]; los estudios de Conrad Vilanou Torrano y Jaume Bantulà Janot desde la historia de la cultura y de las ideas [Vilanou, Conrad y Bantulà, Jaume: «Sobre la 
estudios que sitúan el juego en el centro del debate historiográfico, ya sea desde la historia de la infancia, la historia de la educación física, la historia cultural, la renovación pedagógica o la historia de la educación en general.

La actividad lúdica es un elemento de educación integral de primer orden, pues favorece el desarrollo tanto de la educación intelectual o cognoscitiva, como de la educación física o corporal, la educación estética y creativa-como es el caso de los juegos populares y tradicionales que nos ocupan en el presente trabajo- y la educación social y/o cívica. Como veremos con posterioridad, estos juegos han centrado la atención de los educadores y educadoras en nuestro contexto, principalmente en los períodos de renovación pedagógica. El juego contiene elementos consustanciales a una «educación nueva» tales como el activismo, la globalidad o integridad, la motivación e interés, la significatividad, la coeducación, la libertad, etc. No es de extrañar pues que aquellos formadores que nos han precedido interesados en una acción educativa paidocéntrica y renovada prestaran una atención especial a la actividad lúdica, bien como recurso educativo, bien como principio pedagógico. Asimismo, conviene remarcar que el juego es una actividad natural y, por lo tanto, un recurso económico al alcance de todos. Si bien requiere de una serie de materiales (juguetes o materiales de juego), espacios (en el caso de los juegos populares y tradicionales, preferentemente al aire libre), compañeros (jugadores) y tiempo, estos elementos se encuentran fácilmente en

eutrapelia o la virtud del juego: moralidad, historia y educación», Bordón. Revista de Pedagogía, vol. 65, I, pp. 47-58; Bantulà, Jaume y Vilanou, Conrad: «Joc, humanisme i pedagogia: la virtut de l'eutrapèlia", Aloma: revista de psicologia, ciències de l'educació $i$ de l'esport, 25 (2009), pp. 53-89; BANTULÀ, Jaume: «Una mirada a l'home que juga», Aloma: revista de psicologia, ciències de l'educació $i$ de l'esport, 25 (2009), pp. 15-27; BANTULÀ, Jaume: «Per una pedagogia del joc: la seva aposta educativa des del segle XIX», Revista catalana de pedagogia, 6 (2007-2008), pp. 36I-380; BANTULÀ, Jaume: «El Joc popular i tradicional als segles XVI i XVII: revisió des d'una perspectiva taxonómica», Educació i història: Revista d'història de l'educació, 8 (2005), pp. I34-I46; BANTULÀ, Jaume: «En torno al "enseñar deleitando" de Horacio", La educación revisitada: ensayos de hermenéutica pedagógica (2010), pp. 59-69]; o de Andrés Payà Rico, sobre la historia de la educación, la historia de la infancia, la renovación pedagógica y los juguetes educativos [PAYÀ, Andrés: «Joc corporal, esport i educación física a l'ideari pedagògica de la Institución Libre de Enseñanza", Educació $i$ Història. Revista d'Història de l'Educació, 7 (2004), pp. II7-I33; PAYÀ, Andrés: La actividad lúdica en la Historia de la Educación española contemporánea, Valencia, Universitat de València, 2007; PAYÀ, Andrés: «Consideraciones pedagógicas sobre los valores y posibilidades educativas del juego en la España contemporánea (1876-1936)", Historia de la Educación. Revista Interuniversitaria, 26 (2007), pp. 299-325; PAYÀ, Andrés: «El juego como recurso de educación moral y cívico-social», Revista de Ciencias de la Educación, 209 (2007), pp. 75-I00; PAYÀ, Andrés: Aprender jugando. Una mirada histórico-educativa, Valencia, Universitat de València, 2008; PaYÀ, Andrés: «Joc i cultura del poble valencià: dos textos dels segles Xvir i xviII», Temps d'Educació, 34 (2008), pp. 205-220; PAYÀ, Andrés: «Jugar a la guerra i a la pau. Breu història dels discursos ludicopedagògics en els segles XIx $\mathrm{i}$ XX», Aloma. Revista de psicología, ciències de l'educació i de l'esport, 25 (2009), pp. I19-136; PAYÀ, Andrés: «O xoguete educativo español no século xx», Revista Galega de Educación, 5I (20II), pp. 44-47; PAYÀ, Andrés: «Aprender deleitando. El juego infantil en la pedagogía española del siglo XX», Bordón, 65, vol. I (2013), pp. 37-46; PAYÀ, Andrés: «Juego, juguete y educación en la pedagogía española contemporánea», Espacios en Blanco, 24 (2014), pp. I07-I26; PAYÀ, Andrés: «El juego y el juguete en la historia de la escuela», en MAYORDOMO, Alejandro y BARBERÀ, Óscar (eds.): Escoles i mestres: dos siglos de historia y memoria en Valencia, Valencia, PUv, pp. 136-152, 2017]. 
un entorno educativo, el cual, con pequeñas acciones, se puede transformar en un 'caldo de cultivo lúdico' o campo de juegos. Por estas y otras razones que iremos analizando a continuación, han sido muchos los educadores que a lo largo de la historia de la educación han ido recurriendo al juego como elemento formativo y pedagógico, fruto de una mentalidad preocupada por la infancia que pretendía sustituir la tradicional sentencia de 'la letra con sangre entra' por el ideal del 'aprender deleitando'.

En el caso que nos ocupa como objeto de estudio en el presente trabajo, los juegos populares y tradicionales, cabe reseñar además que estas actividades lúdicas forman parte de la identidad cultural y del patrimonio educativo inmaterial de una sociedad. Así como los cuentos infantiles y las leyendas populares, los refranes, las canciones o las festividades, estos juegos pertenecen al pueblo, a las sociedades que los hacen suyos y los interiorizan, formando y conformando identidad y facilitando la integración, la inclusión y la apropiación cultural. Los juegos populares devienen entonces en tradicionales porque, como tales, con el paso de los tiempos, son transmitidos, jugados y conocidos intergeneracionalmente, pudiendo así 'aprender jugando' fácil y plácidamente los distintos códigos culturales y socializarse jugando los mismos juegos que sus antepasados. Por ello, podemos afirmar que estos juegos son parte del currículo que las sociedades han ido legado a los más jóvenes como parte de la cultura o culturas de una sociedad.

\section{Los juegos populares y tradicionales en la educación social}

Como acabamos de comentar, la actividad lúdica es un recurso pedagógico de educación integral natural y motivadora difícilmente mejorable. En el presente estudio, centraremos nuestra atención en uno de estos aspectos (aún conscientes de que el todo es mayor que la suma de las partes) de la educación integral: la educación social, moral y/o cívica. El juego popular es quizás el tipo de juego que está más presente en cualquier organización social y cultural, por su arraigo y por representar parte de las tradiciones y costumbres de un colectivo, estando siempre disponible y al alcance de cualquier educador. Los juegos populares tienen una gran antigüedad y han sido siempre, consciente o inconscientemente, uno de los primeros elementos de socialización de todo infante, cuya práctica le permite pasar de un ser individual a un ser social. Mediante esta actividad lúdica los jugadores se introducen en las normas y costumbres de su cultura. Por ello, es nuestra intención en este trabajo mostrar el interés pedagógico que estos juegos han suscitado a lo largo de nuestra historia contemporánea, ofreciendo una serie de ejemplos y deteniéndonos en alguna de sus aplicaciones y manifestaciones educativas, a nuestro juicio más interesantes o relevantes. 
2.I. Los juegos populares y la educación en Europa a finales del s. XIX y principios del XX. Un ejemplo a imitar

Comenzamos dicho recorrido histórico-educativo a finales del siglo xIX, cuando el ovetense de influencia krausista Adolfo Alexis Buylla, atento a los excelentes resultados obtenidos por la iniciativa de Daryl como secretario de la Liga para la propagación de los juegos físicos en Francia, reclama para España la práctica bajo aspectos pedagógicos de los juegos tradicionales, considerando que «apenas si se necesitaba introducir en nuestro país modas extrañas, teniendo, como tenemos, en casi todas las provincias, la pelota, los bolos, el salto del puente, el pio campo»3. En un artículo del institucionista y secretario del Museo Pedagógico Nacional Ricardo Rubio, también se toma como ejemplo y referencia a educadores franceses como Lagrange, Daryl o Coubertin, y a su labor de recuperación lúdico-pedagógica con la creación de "la "Sociedad para la propagación de los ejercicios físicos en la educación", y la "Liga nacional de la educación física", cuya tendencia era despertar el interés de la juventud por los antiguos juegos franceses, en desuso á causa del creciente predominio de la educación intelectualista»4. En este mismo sentido, también Pedro de Alcántara García es consciente del auge que por entonces tienen los juegos tradicionales en países europeos como Alemania, Suiza, Bélgica, Francia y, especialmente, Inglaterra, recomendando los más populares de entre estos junto a los autóctonos españoles para su práctica en las escuelas de nuestro país:

Partiendo en cada país de los locales, son en todos organizados, en cuanto que se recomiendan como los mejores para el fin que se persigue, los de pelota (éstos, con ser muy variados y eficaces, son muy nacionales entre nosotros y muy conocidos y del gusto de los niños), de los bolos, del marro, del escondite, de justicias y ladrones, de liebres y lebreles, y, en general, todos los llamados de partido, por el ardor y atractivo que imprime la lucha á que invitan: el crocket, el cricket, el foot ball, son juegos ingleses muy recomendables, que empiezan á figurar al lado de los nuestros ${ }^{5}$.

Unos años después la maestra valenciana de enseñanza superior Natalia Castro de la Jara, en respuesta al tema tercero de la Asamblea del Magisterio de Sevilla, Valencia y Barcelona de I895, sobre los juegos más adecuados para la formación física y del carácter de las niñas en las escuelas, fija su mirada sobre los juegos populares, incidiendo especialmente en el archiconocido juego del marro ${ }^{6}$,

Buylla, Adolfo Alexis: «El libro de M. Daryl sobre la educación física», Boletín de la Institución Libre de Enseñanza (BILE), 296 (I889), pp. 162-163.

4 Rubio, Ricardo: «Los juegos corporales en la educación», BILE, 39I (I893), p. I46.

s García, Pedro de Alcántara: «El renacimiento de la educación física», La Escuela Moderna, 7 (I89I), pp. 486-487.

6 Véase Brasó, Jordi y Torrebadella, Xavier: «"El marro”, un juego tradicional y popular en la educación física española...», op. cit., y BRAsó, Jordi y Torrebadella, Xavier: «El juego motor del marro: una indagación acerca de sus raíces...», op. cit. 
así como el juego inglés de los perros y las liebres ${ }^{7}$. La revista La Escuela Moderna ${ }^{8}$, en su sección dedicada a la crónica del exterior, se hace eco de la experiencia de la localidad francesa de Chauny, donde se funda una Sociedad de renovación de los juegos populares, la cual tiene por objeto «vulgarizar los antiguos juegos franceses y los nuevos que puedan originarse, y por este medio distraer al pueblo, reuniéndolo en la plaza pública, al aire libre [...] No puede darse propósito más culto y saludable, así para lo físico como para lo moral»`. Estos argumentos pedagógicos y moralizadores llevan a la revista a defender la necesidad de imitar esta iniciativa francesa también en nuestro país, puesto que «en España, donde tanta vida de tabernas y café se hace, sería obra muy estimable y civilizadora, la de hacer también todo lo posible por vulgarizar, despertando la afición hacia ellos» ${ }^{\circ}$. En esta misma línea moralizadora, el médico e higienista Philippe Tissié (introductor de los juegos organizados y los deportes en la escuela francesa junto a Pierre de Coubertin y Paschal Grousset), en un libro traducido al español por Ricardo Rubio, llama la atención sobre el carácter pedagógico y socializador del juego popular de pelota en los frontones y trinquetes del País Vasco en I899, «el juego es una escuela de virilidad y de respeto en la cual viene el vasco á tomar su fuerza y á refrescar su independencia ${ }^{\text {", }}$ una actividad lúdico-deportiva la de la pelota, arraigada y practicada con sus variantes en otras partes del territorio español (como es el caso, por ejemplo, de la pilota valenciana) ${ }^{12}$.

A comienzos del siglo xx, el maestro renovador valenciano de la Escuela Superior de Cartagena, Félix Martí Alpera, buen conocedor de las escuelas europeas de la época ${ }^{13}$, se aflige por la triste situación en la que se encuentra la práctica lúdica en nuestro país, siendo consciente de que la «desaparición de nuestras costumbres revela nuestra bancarrota moral y física. En España no jugamos; en España huimos del aire, de la luz, del ejercicio [...] El porvenir de nuestros descendientes despierta en todo cerebro sano multitud de sombríos presentimientos. Parécenos

7 Castro, Natalia: «Educación física de las niñas», La Escuela Moderna, 49 (I895), p. 297.

8 Montes, Soledad: “La Escuela Moderna”. Revista pedagógica Hispano-Americana (I89I1934)», Historia de la educación. Revista Interuniversitaria, I9 (2000), pp. 413-429.

9 «Crónica del exterior», La Escuela Moderna, 65 (I896), p. 157.

ro Ídem.

" TissiÉ, Philippe: La fatiga y el adiestramiento físico, Madrid, Librería de Fernando Fé (traducción española de Ricardo Rubio), I899, p. 433.

${ }_{12}$ Monforte, Enric: Una reconstrucció del joc de pilota valenciana als pobles de la comarca de l'Horta Sud de València de I900 a 1975: una investigación des de la historia oral, tesis doctoral, Universitat de València, 20I5.

${ }_{13}$ Véase Moreno, Pedro Luis: «Renovación Pedagógica y compromiso social en la edad de plata de la Pedagogía española: Félix Martí Alpera (1898-1920)", Revista Española de Pedagogía, vol. 63, 23I (2005), pp. 203-222; SolER, Joan: «Por las escuelas rurales de Europa: las aportaciones de Félix Martí Alpera», SÁNchez, Felicidad (coord.), en Relaciones internacionales en la Historia de la Educación, Cáceres, sedHe y Universidad de Extremadura, vol. 2 (2007), pp. 355-368; Moreno, Pedro Luis: «Maestros renovadores, maestros viajeros: Félix Martí Alpera», en García Velaso, José y SÁnchez, José Manuel (coords.): roo JAE: la Junta para Ampliación de Estudios e Investigaciones Científicas en su centenario, Madrid, Residencia de Estudiantes, vol. 2, 20Io, pp. 758-789. 
asistir á la agonía de una raza» ${ }^{14}$; un escenario que no encontrará solución más que en la difusión de los juegos populares, siendo necesario «ahuyentar la muerte que se acerca y que los lúgubres horizontes que divisamos se conviertan en consoladoras perspectivas, si queremos ser un pueblo sano, fuerte, enérgico, animoso y bien equilibrado, mejoremos nuestras costumbres, volvamos á nuestra santa madre la Naturaleza, pasemos los días festivos en el campo, y en vez de trabajar como niños y jugar como hombres, trabajemos como hombres y juguemos como niños» ${ }^{15}$. En otro artículo publicado en 1900 con el mismo título («Lo que deben ser los juegos de los niños») y en la misma revista, la pedagoga y escritora institucionista Matilde García del Real, tras observar el deplorable panorama de la práctica de juegos tradicionales españoles, ofrece una serie de pautas y conclusiones, entre las que destaca el señalar que deben promoverse la realización de concursos en que «jugadores de cada región española, y aun extranjeros, demuestren y enseñen los juegos característicos de su país. Estos concursos, presenciados por Maestros y alumnos de las Escuelas Normales y Superiores, serían de grandísima utilidad $»^{16}$, pudiendo aprovechar posteriormente los educadores asistentes estos juegos populares como recurso para la educación social en las escuelas. El mismo Manuel Bartolomé Cossío es otro de los educadores que también reclama para los juegos populares españoles una mayor atención, utilizando como ejemplo el juego tradicional vasco, invitando a los educadores a su uso pedagógico para una reconstrucción nacional y formación del carácter, propia de la mentalidad regeneracionista del momento:

Yo, en este pueblo, en este país vasco, donde más que en ningún otro punto de España se ha conservado el juego entre todas las clases sociales, el juego sano y noble, el juego corporal al aire libre; donde hasta hace poco tiempo, según creo, se veía jugar al alcalde y al médico, al juego y al sacerdote, yo os digo: restaurad vuestros juegos, que van á morir, como muere toda función social cuando cae en exclusivas manos de profesionales; y para restaurarlos, enseñad á jugar á vuestros hijos; que más cuesta -y os lo aseguro por dolorosa experiencia- enseñar á jugar (á jugar de veras, que es cosa muy diversa de juguetear y divagar) que á estudiar, á los niños españoles ${ }^{17}$.

De otro lado, a propósito de la dinámica educativa de las escuelas al aire libre en las cuales este tipo de juego encuentra un perfecto acomodo y el espacio ideal para su práctica, el pedagogo y futuro ministro de Instrucción Pública y Bellas Artes durante la Segunda República Domingo Barnés recalca también en I9ıo el papel formativo de carácter social y moral que pueden llegar a alcanzar los juegos

${ }_{14}$ Martí, Félix: «Lo que deben ser los juegos de los niños», La Escuela Moderna, iıo (I900), pp. 367-368.

is Ibidem, p. 368.

16 García del Real, Matilde: «Lo que deben ser los juegos de los niños», La Escuela Moderna, III (I900), p. 43I.

${ }^{17}$ Cossío, Manuel Bartolomé: «El maestro, la escuela y el material de enseñanza», BILE, n. ${ }^{\circ} 559$ (1906), p. 29I. 
populares, pues en estos establecimientos educativos los niños «juegan los clásicos juegos del país, esos juegos corales tan ingenuos, y que bien dirigidos son verdadera escuela de distinción, de finura, de disciplina, de serenidad, de gracia y de buenas maneras ${ }^{{ }^{8}}$. Todas estas virtudes sociales y morales de los juegos populares y tradicionales son ensalzadas también por el belga Sluys, el cual hace un análisis de los juegos populares de Bélgica que podría ser igualmente válido para el caso español, pues es evidente que por entonces, aunque los juegos tradicionales de los niños y de los adolescentes son muy numerosos, «tienden á desaparecer, á consecuencia de las condiciones de la vida moderna; es útil, para asegurar los fines de la educación, que la escuela ayude al renacimiento de los juegos populares» ${ }^{19}$; para ello, da una serie de recomendaciones y prácticas pedagógicas como, por ejemplo, el que «el programa de los juegos se sacará principalmente de los juegos tradicionales locales: los que han sido practicados por los niños durante siglos, responden, en efecto, mejor á sus necesidades instintivas. Fuera de los juegos locales, existen juegos practicados en el extranjero y que, á causa de sus cualidades educativas, pueden figurar en un programa escolar ${ }^{20}$. Como se puede apreciar por la constante alusión a la realidad lúdica de otros países europeos, los juegos populares españoles se encuentran en contraposición muy olvidados, más aun cuando se compara con otros países como Italia, donde se atiende al «carácter de los juegos italianos populares de la infancia; a la oportunidad de sustituir los juegos que inventó el espíritu abstracto de los teorizantes por los que han nacido de la secular experiencia popular nutridos de canciones sugestivas, ficciones dramáticas sencillas y juguetonas, sorpresas gratas a los niños; a la necesidad de depurar, mediante una delicada selección, los juegos populares tradicionales de las distintas comarcas de todo aquello que sea menos noble y educativo» ${ }^{21}$.

\subsection{Los 'jocs populars i tradicionals' en Cataluña. La vanguardia lúdica de renovación pedagógica}

Como veremos a continuación, Cataluña fue el lugar del territorio español en el cual caló mejor el mensaje europeísta sobre la recuperación del patrimonio lúdico y se pusieron cuanto antes manos a la obra para poner en valor y emplear los juegos populares y tradicionales en la educación. En el primer tercio del siglo $\mathrm{xx}$, como ocurrió con otras iniciativas de renovación pedagógica, los educadores catalanes fueron la vanguardia lúdica del país. En este sentido, el pedagogo de la Escuela Nueva Eladi Homs aboga en 1912 por una necesaria labor de recuperación del patrimonio lúdico para una mejor socialización y aprendizaje de la cultura propia, seleccionando, entre otras actividades físicas y deportivas, los

I8 BARNÉs, Domingo: «Escuelas al aire libre», BILE, n. 605 (1910), p. 242.

19 SLuYs, Alexis: «Los programas de educación física en la escuela belga», BILE, 6IO (I9II), p. I5.

20 Ibidem, pp. I5-I6.

${ }^{21}$ Lombardo-Radice, Giuseppe: «El folklore y la educación de los niños en Italia», Revista de Pedagogía, 8I (1928), pp. 385-386 


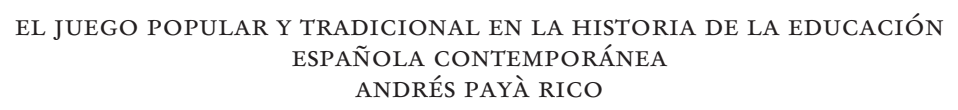

juegos populares y tradicionales «para resucitar olvidados juegos y actividades primitivas de la raza $»^{22}$. Al respecto, el también catalán Antoni Sabater Mur con motivo del anuncio en 1918 de la Associació Protectora de la Ensenyança Catalana, que ofrece un magnífico premio a la mejor recopilación de juegos populares para los niños y niñas de tierras de lengua catalana ${ }^{23}$, realiza una serie de interesantes críticas y observaciones en las que duda de su carácter pedagógico:

Si el juego tuviese la eficacia educativa que tan gratuitamente se le atribuye, difícilmente habría pueblo que pudiese compararse al nuestro, ya que nuestros niños juegan (a su modo, claro está) de un modo incomparable. Es incalculable el número de juegos de nuestro folklore, pero ¿qué les debemos a esos juegos? No será el progreso de nuestra raza que -ya lo hemos repetido varias veces-, tiene a gloria librarse del servicio militar por falta de desarrollo físico. No será el nivel intelectual que pregona nuestro analfabetismo. No será nuestra elevación espiritual que se manifiesta en la falta absoluta de fe dentro de nuestra religiosidad [...] Nuestros juegos infantiles se fundan casi todos (cuando menos los preferidos por los niños) en su falta de orden, se caracterizan en que cada cual juega como quiere, y tienen los jugadores, como única sanción, los golpes de sus compañeros, Si algún juego requiere una disciplina como el Marro, no se tarda en faltar a ella ${ }^{24}$.

Estas y otras declaraciones son una muestra evidente de un fenómeno obvio y ya conocido como es el de la renovación pedagógica que vive Cataluña en estos años, cuyos esfuerzos a favor del restablecimiento de los juegos populares son un buen ejemplo de ello. En este sentido, como informa María de Borja, el conocido etnólogo y folklorista Joan Amades realizará por entonces una recopilación de juegos populares, desde el convencimiento de que

Los juegos de palabras tienen a nuestro juicio, un verdadero valor filológico y constituyen una importante rama de la lingǘstica folklórica que es necesario que no sea abandonada ni menospreciada en el estudio de la lengua. Los juegos de memoria, documentos de creación popular de una gracia excelsa y un ingenio maravilloso, constituyen elementos interesantes de carácter etnológico y poseen una gran importancia filológica; carecen, pero, del valor lingüístico de los juegos de palabras ${ }^{25}$.

La ciudad de Barcelona será un verdadero ejemplo en los años 20 de recuperación y promoción del juego popular catalán, realizando un esfuerzo encomiable por promocionarlo y por establecer las condiciones idóneas para su práctica

22 Homs, Eladi: «La educación extra-escolar», BILE, 629 (I9I2), p. 245.

${ }_{23}$ Sobre este concurso, María de Borja ofrece el siguiente fragmento traducido al castellano: «Consciente del valor educativo del juego y de que hay un gran número de juegos infantiles que son un tesoro folklórico poco conocido. La Associació Protectora de l'Ensenyança Catalana quiere hacer una recopilación de estos juegos para ofrecerlo a padres y educadores». BoRJA, María de: $E l$ juego como actividad educativa. Instruir deleitando, Barcelona, Publicaciones de la Universidad de Barcelona, 1984, p. 79.

24 SAbater, Antoni: «Juegos infantiles», Boletín del Liceo Escolar (Lleida), II4-II5 (I9I8), pp. 2-5.

25 Borja, María de: El juego como actividad educativa..., op. cit., p. 82. 
desde el pensamiento de que estos juegos son una parte muy importante de la difusión cultural y socialización en los usos y costumbres catalanas. Tal es el caso de las escuelas al aire libre de Montjuic, las cuales incluyen entre su programación pedagógica este tipo de actividades lúdicas, indicando cómo «s'ha fet una selecció dels jocs, donant preferencia als tradicionals en el país i proscrivint els perillosos o grollers ${ }^{26}$. En esta misma dirección también actúan los jardines de infancia dependientes del Ayuntamiento barcelonés:

Aquesta direcció que exerciria la institució de jardins i camps de joc d'infants en el joc dels nostres nois podria dur a terme una obra tan interessant com és la del restabliment del nostres jocs populars que tant podria contribuir a retrobar la nostra ànima amb l'abundor de llegendes d'història i de costums que contenen [...] Majorment interessant fora aquesta obra, quan a Barcelona hem anat deixant perdre aquests jocs $\mathrm{i}$ els hem anat suplint per altres d'estrangers, moltes vegades de no tan bon gust, i sempre desplaçats dintre la manera d'ésser del nostre poble. Avui a Barcelona ja no existeix cap joc dels nostres, i per a restablir-los tots es farà ja necessari de fer alguna excursió cap als pobles rurals més llunyans de les grans ciutats, que és a on es conserven encara lliures i purs del contagi d'aquells jocs importats de fora. Afortunadament no manquen particulars i fins algunes entitats que es captenen amb zel d'anar recollint els nostres jocs populars i d'una manera molt especial la Protectora de l'Ensenyança Catalana ${ }^{27 .}$

Sin abandonar la capital catalana, el testimonio de una maestra de las Escuelas Nacionales de Barcelona, María Baldó, refleja claramente la importancia del juego libre y espontáneo entre los juegos populares, por ser una síntesis educativa para la infancia, «ésta queda mucho más definida si buscamos para nuestros alumnos aquellos juegos populares que a su espontaneidad juntan la ley de herencia a que representan por ser propios de nuestro pueblo» ${ }^{28}$; advirtiendo a toda la comunidad educativa, y en especial a los docentes, que el maestro «hará un buen servicio a la obra educativa recogiendo los juegos populares de su localidad y transformándoles en motivo educacional que proporcione al niño el esparcimiento biológico que precisa y la formación anímica que le hace falta ${ }^{29}$. No solamente desde el magisterio y la pedagogía catalana se aboga por el empleo de los juegos populares en la educación, también reconocidos folkloristas como Francesc Maspons ${ }^{30}$ o Rosend Serra i Pagés prestan una especial atención a esta actividad lúdica, pues como indica este último, en un texto recogido por Marín y Pardo, una de las partes más importantes «del cabal tradicional dels pobles és la relativa a la dels costums de les criatures i no solament per la simpatia que inspiren

26 Ajuntament de Barcelona: Escoles a l'aire lliure del Parc de Montjuic, Barcelona, Ajuntament de Barcelona, I92I, p. 39.

27 Ajuntament de Barcelona: Els jardins dels infants, Barcelona, Comissió de Cultura de l'Ajuntament de Barcelona, 1920, p. 52.

28 BALdó, María: «El folklore en la escuela», Revista de Pedagogía, 43 (1925), p. 298.

29 Ibidem, p. 299.

30 Maspons, Francesc: Jocs d'infants, Barcelona, Editorial Barcino, 1928. 
ANDRÉS PAYÀ RICO

totes llurs manifestacions, que és absoluta, i per l'indiscutible valor pedagògic que tenen, sinó pel carácter de permanencia que ostenten, havent trobat a l'efecte els folkloristes més eminents que els jocs infantils guarden les supervivències de les edats i civilitzacions més reculades» ${ }^{31}$. Estas iniciativas de recuperación del patrimonio lúdico catalán fueron imitadas con el tiempo en otros lugares vecinos, como ocurrió en Aragón, donde el maestro Felipe Castiella, al tratar el tema de los juegos infantiles más adecuados para practicar en el aula, insta también al aprovechamiento y la recopilación de juegos populares autóctonos:

Es innecesario advertir que para la enseñanza de los juegos se recomienda por sí mismo el método activo. Abundan los juegos infantiles en el 'folklore' nacional -algunos característicamente regionales-; y resultaría una labor útil y meritoria en alto grado el que personas especializadas en estos asuntos se dedicasen a la tarea de recopilarlos en un libro que, sin duda alguna, sería muy solicitado por los padres y educadores de la infancia ya que éste es un tema tratado muy a la ligera por nuestros publicistas y escritores ${ }^{32}$.

\subsection{Juegos populares y tradicionales en el franquismo. Patria e identidad nacional a través del juego}

Como ocurre con otras actividades que sirven para la exaltación patriótica y la construcción de un carácter nacional y racial (himnos, catecismos políticos, tradiciones, conmemoraciones, etc.), los juegos populares propios del folklore español serán objeto de recuperación y uso educativo-adoctrinador tanto antes como después de la Guerra Civil. En este sentido, en 1935 el inspector, y creador posteriormente del CEDODEP, Adolfo Maíllo ya apuntaba hacia el estudio de este tipo de tradiciones y actividades lúdicas, para «completarle en sentido folklórico, racialista, tomando como base los juegos típicos de cada región, porque las actividades espontáneas del pueblo en que el decurso de los tiempos se perpetúan invariables, obedecen a un principio de adecuación perfecta al alma racial, que es necesario tener siempre en cuenta para hacer eficaz y fecunda, en el espacio y en el tiempo, la labor de la escuela» ${ }^{33}$. Del mismo modo, ya en pleno franquismo, en la década de los 40, Sánchez Múgica destaca los juegos populares españoles como un instrumento extraordinario de formación nacional, realizando una recuperación de estos bajo la justificación de que «la misma variedad que se observa en las costumbres y folklore en nuestras provincias la encontramos en los juegos españoles [...] Por esto, nuestro deseo de dar a conocer en estas páginas el mayor número posible de ellos, con el fin de proporcionar al compañero Maestro un buen medio educativo» ${ }^{34}$. Entre esta recopilación de juegos populares,

${ }^{31}$ Marin, Imma y Pardo, Olga: El jugar de l'Amades. Cultura d'infants. Volum i: Moixanes, cançons de sorteig i jocs, Tarragona, Edicions El Mèdol, I996, p. I4.

32 Castiella, Felipe: «Los juegos infantiles», Revista de Pedagogía, 92 (1929), p. 345.

33 Maíllo, Adolfo: Nociones de pedagogía, Madrid, El Magisterio Español (2. ${ }^{a}$ edición), i935, p. II5.

34 Sánchez, Rafael: «Educación física», La Escuela en Acción, 7.504-7.505 (1947), p. 27. 
propondrá en sucesivas publicaciones de la revista La escuela en acción, juegos de exaltación patriótica y favorecedores de la unidad nacional como, por ejemplo, el juego del 'churro' bajo una denominación diferente, en el que el capitán del bando contrario empieza el juego al grito de «España número I»35. La amplia y rica variedad de juegos populares que recopila Sánchez Múgica, así como el entusiasmo nacionalista, le hacen llegar a la siguiente conclusión: «Muchos son los juegos que llevamos ya indicados en las páginas de LA ESCUELA EN ACCIÓn; mas son tan variados los practicados por los niños españoles en las diversas regiones y provincias, que difícilmente habrá en el mundo pueblo que los supere» ${ }^{36}$, una curiosa conclusión a la que llegan varios países que se consideran asimismo como hemos visto, cada uno de ellos, poseedores de la mayor diversidad y patrimonio de juegos populares existente.

Durante la dictadura franquista, las diferentes publicaciones pedagógicas periódicas (La Escuela en Acción, Escuela Española, El Magisterio Español, Boletín de la Inspección de Enseñanza Primaria, Revista de Educación, etc.) aprovecharán cualquier oportunidad para realizar en sus páginas una apología y ensalzamiento patrio, siendo los juegos populares uno de los elementos ideales para alcanzar las conciencias infantiles, «nuestros juegos populares nunca deben caer en el olvido, ni ser postergados por otros de importación. Muy bien el base-ball, el hand-ball, el baloncesto y tantos otros de origen norteamericano o inglés que han venido a enriquecer nuestros sistemas de recreo, pero no olvidemos nunca ni la pelota, ni el marro, ni los bolos, ni tantos otros juegos propios de España» ${ }^{37}$. Se parte de la convicción de que el mero hecho de practicar estos juegos populares afianzará el carácter nacional-catolicista, lo cual parece posible porque «en España tenemos una tradición riquísima en canciones, bailes y juegos cuya conservación puede contribuir a que permanezca y aun se haga más fuerte el sentido cristiano de la vida española» $3^{8}$.

La recuperación del patrimonio lúdico inmaterial tradicional que conforman los juegos populares se extiende también a una preocupación por el patrimonio lúdico material, abogando por la perentoria necesidad de fabricar juguetes de producción española que tengan presentes los criterios de bondad y características de los juegos populares, «evitaremos las perniciosas influencias extranjerizantes que desvirtúan los gustos estéticos de nuestros pequeños y lograremos un éxito completo cuando, llegada la época de los Reyes Magos, acertemos con el obsequio apropiado para el alma delicada de nuestros niños» ${ }^{39}$. El discurso nacionalista y patriótico durante las primeras décadas del franquismo es constante, realizando una gran difusión y poniendo en marcha acciones de propaganda para que los niños y jóvenes españoles practiquen los juegos populares propios de su

35 SÁnchez, Rafael: «Juegos escolares», La Escuela en Acción, 7.517-7.518 (1947), p. 84.

36 SÁnchez, Rafael: «Juegos escolares», La Escuela en Acción, 7.762-7.763 (1950), p. 192.

37 «Juegos y deportes. El marro», Niños de Escuela Española (suplemento infantil de la revista Escuela Española), 59, II marzo 1948, p. 3.

38 «Diversiones y cultura», Escuela Española, 378 (1948), p. 491.

39 «Valor educativo del juguete», El Magisterio Español, 7.77I (1950), p. 244. 
ANDRÉS PAYÀ RICO

país, a pesar de lo cual hay quien considera en I964 que «se ha menospreciado un poco hasta el presente ese venero bien abundante del juego tradicional, conocido desde nuestra infancia - para los ya veteranos-, tan rico en buenas calidades de todo orden y de efectos tan saludables así física cuanto moralmente» ${ }^{40}$, reivindicando su utilización mediante la explicación de juegos como el gua, las canicas, la peonza, el zurriago, las cuatro esquinas, la pídola, el salto del burro, etc. Estos motivos llevan al catedrático de Pedagogía de la Universidad de Barcelona Joan Tusquets a solicitar la implantación escolar de los «juegos nacionales» por los beneficios que reportarían a la vida social y comunitaria:

Valiéndonos de todos los medios a nuestro alcance, sin excluir los juegos y la ponderada crítica de su significado, de su efecto y de su puesto exacto en la jerarquía de valores, deberíamos contribuir los pedagogos intencionales - desde el hogar, la escuela o el púlpito -y funcionales -desde la televisión, el cine, el periódico o el cartel anunciador- a que el pueblo y singularmente la juventud se convenzan de que si los españoles estimamos, intelectual y sentimentalmente, el auténtico «lucimiento» en vez de la majeza, la temeridad o el desplante, y no obstaculizamos el «lucimiento» colectivo, a fuerza de preocuparnos del individual, nos habrá caído a todos, no sólo a un afortunado, el premio gordo de la lotería ${ }^{41}$.

\subsection{El patrimonio lúdico español como recurso educativo}

A finales de los años 70, prosigue en nuestro país la invitación a la recuperación y el uso del patrimonio lúdico popular español, si bien con un discurso diferente y lenguaje mucho más moderado. Así, en el II Congreso Internacional sobre el juego y el juguete en el ámbito de la escuela y la educación especial, celebrado en la ciudad de Barcelona del i9 al 2i de noviembre de 1977, se establece entre las conclusiones relativas al ámbito escolar que «urge la realización de trabajos de investigación que recopilen los juegos tradicionales y populares infantiles, recogiendo la información necesaria (nombre con que se le conoce según los lugares, normas del juego, condiciones...) que asegura la continuidad de su transmisión» ${ }^{42}$. La explotación pedagógica de los juegos tradicionales de cada país es también uno de los motivos que llevan a un organismo como la UNESCO a publicar un libro al respecto, editando una monografía «sobre el aprovechamiento de las tradiciones culturales nacionales para concebir y establecer técnicas de educación adaptada al medio» ${ }^{43}$, adaptándose la actividad lúdica tradicional o popular, mejor que ningún otro instrumento pedagógico, a la peculiaridad y singularidad de cada cultura o sociedad.

40 «Juegos en la Escuela», Boletín de la Inspección de la Enseñanza Primaria, 24 (1964), p. 9.

${ }_{41}$ TusqueTs, Joan: «Juegos nacionales y pedagogía del desarrollo», Revista de Educación, i85 (1966), p. 85.

${ }_{42}$ «Conclusiones del in Congreso Internacional sobre el juego y el juguete en el ámbito de la escuela y la educación especial», Bordón, 222 (1978), p. 188.

${ }^{43}$ UNESCO: El niño y el juego. Planteamientos teóricos y aplicaciones pedagógicas, París, UNEsco, I978, p. 3 . 
Con la aprobación de la Constitución española en 1978 y el reconocimiento de las diferentes comunidades autónomas se exhorta a recoger la pluralidad y aprovechar la riqueza lúdica y cultural de cada uno de estos territorios. En este sentido, el pedagogo gallego Jurjo Torres señala a las ludotecas como instituciones de juego ideales donde poder acoger esta pluralidad lúdica por su vinculación al medio sociocultural en el que están insertas, sirviendo en este sentido «para la recuperación de los juegos populares como patrimonio cultural de valor incalculable» ${ }^{44}$. Por entonces las iniciativas en las diferentes comunidades autónomas se multiplicarán exponencialmente, realizándose un gran número de com-

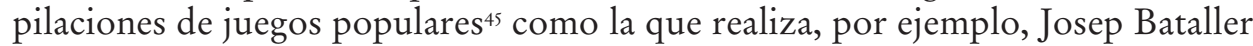
desde el Instituto de Ciencias de la Educación de la Universitat de València, en cuyo prólogo, firmado por el filólogo e historiador Manuel Sanchis Guarner, se puede leer que «l'escola, doncs, ha de prestar atenció als jocs infantiles tradicionals peculiars de cada comunitat, i no limitar-se a la difusió i fonament d'altres forasters, els quals serien -han estat-alienants» ${ }^{46}$. Por su parte, el estudioso catalán del juguete José Corredor-Matheos se replantea la validez de los 'nuevos juegos' frente a los tradicionales, creyendo necesario saber si, «rotas las barreras que separan a un niño de otro en algunos de los modernos juegos, este tipo de juegos será un sustituto válido de los juegos tradicionales y capaz, por lo tanto, de cumplir la doble función de permitir la creatividad del niño y de divertirle» ${ }^{47}$. Desde el punto de vista de Corredor-Matheos, la moderna sociedad de los años 80 y las demandas consumistas cada vez más exigentes de los niños de la época, tienen gran parte de culpa en la desaparición también de los juguetes más tradicionales:

Moltes d'aquestes joguines, van resistir les innovacions i es van mantenir durant molt de temps. No creiem que els intents de reactualització amb materials diferents de la fusta - plàstics- l'hagin feta reviure. Potser és oportú que diguem, arribats en

44 Torres, Jurjo: «Un espacio para el juego: las ludotecas», Cuadernos de Pedagogía, 57 (1979), p. 23.

45 En este sentido, son muy diversas e interesantes las monografías editadas en las últimas décadas del siglo xx sobre recopilaciones de juegos populares en diferentes lugares de la geografía española. Véanse, entre otras: Andalucía: García Benítez, Antonio: El folklore infantil andaluz: antología de juegos populares, Sevilla, Editoriales Andaluzas Unidas, 1988. Galicia: Romaní, Arturo: Xogos infantiles de Galicia, Santiago de Compostela, Follas Novas, 1979; vv. AA.: Xogos populares en Galicia, La Coruña: Xunta de Galicia, 1986. Baleares: Pou, Antoni: Jocs populars, Palma de Mallorca, Editorial Moll, I980; Barceló, Jaume y Forteza, Lluis: Cançons i jocs populars de les Illes Balears, Palma de Mallorca, Centre d'Estudis d'Esplai, 1993. Canarias: Rodríguez, Alberto: Juegos y canciones tradicionales, La Laguna, Centro de la Cultura Popular Canaria, 1987. Castilla la Mancha: MedinA, María del Carmen: Deportes y juegos populares en Toledo, Toledo, Mc Medina, 1987. Castilla y León: SAnz, Ignacio: Juegos populares en Castilla y León, León, Castilla, 1991. Cataluña: Caballe, Josep y Ruscadella, Toni: Recull de jocs popular gironins, Girona, Servei Municipal de Publicacions, 1982; Marín, Imma: Jocs populars. I tu a què jugues?, Barcelona, Rosa Sensat, 1994. Extremadura: Vizuete, Manuel y Gutiérrez, Juan: Juegos populares extremeños, Mérida, Editora Regional de Extremadura, 1986. Madrid: Jurado, Juan José; Yague, Victoriano y López, Manuel: Juegos de Madrid: los juegos populares y tradicionales como recurso didáctico, Madrid, Caja Madrid, I998; etc.

${ }^{46}$ Bataller, Josep: Els jocs dels xiquets al País Valencià, Valencia, ICE Universitat de València, 1979, p. 6.

47 Corredor, José: «Algunas reflexiones», Cuadernos de Pedagogía, 99 (1983), p. 6. 
aquest punt, que el nen, en les darreres dècades, ha acceptat -en part potser perquè ho reclamava- una major fidelitat als models adults [...] Un cavall ja no serà de cartó sinó que s’assemblarà molt als de veritat. El més important, però, és que ja no veurem gaires cavalls de joguina perquè el mateix nen ja no en veu de debó. Al seu davant té automòbils, autopistes, garatges, cotxes de policia, etc. ${ }^{48}$.

Como se puede apreciar, estos discursos no son más que una muestra de la incesante y continua llamada a rescatar los juegos populares del olvido, a los que se les confiere un potencial formativo de índole social y cívica que podría aprovecharse en las escuelas, puesto que también el patio puede convertirse en «el centro cívico de recuperación de la enorme cantidad de juegos populares, hoy en trance de desaparición. Podemos invitar a nuestros alumnos a que indaguen los juegos que practicaban sus padres y abuelos cuando tenían su edad y después jugarlos en el patio» ${ }^{49}$, utilizando al mismo tiempo estos juegos populares como centro de interés para la explicación e investigación de factores emotivos, históricos e intelectuales. Motivados por estos y otros argumentos, el colectivo vasco de renovación pedagógica Adarra, formado por maestros y maestras interesadas en defender el juego en la escuela pública, también se siente en la necesidad de intervenir pedagógicamente. A mediados de los 80 , ante una situación que califican de pérdida de las tradiciones populares como los juegos y las rondas infantiles, debido a los fuertes movimientos migratorios y mass-media ${ }^{50}$, pasan a la acción con la pretensión de rescatar del olvido aquellos juegos populares que tradicionalmente habían practicado las anteriores generaciones y que tanto provecho educativo y socializador les había proporcionado:

Paralelamente a la progresiva desaparición del juego, de los juegos populares, de los juegos de siempre, se está produciendo en la escuela, entre los enseñantes el «boom» de la expresión corporal, de la psicomotricidad, creatividad, teatro... En muchos casos, pobres sucedáneos con los que se intenta desarrollar «artificialmente» las capacidades que se manifiestan libre y espontáneamente en el juego. Por esto nos parece necesario, incluso vital, la recuperación de los juegos a los que nosotros, nuestros padres y hasta nuestros abuelos nos dedicábamos de pequeños ${ }^{5 \mathrm{~s}}$.

En los años 90, tras un siglo de continuo reclamo de los educadores y educadoras españoles por la introducción de los juegos populares en los currículos escolares, una vez transferidas las competencias educativas a las distintas autonomías, los diferentes decretos que regulan las enseñanzas de educación primaria recogen entre sus objetivos la recuperación y aplicación de los juegos populares propios de cada comunidad. Así, por ejemplo, en las disposiciones legales de Galicia ${ }^{52}$,

8 Corredor, José: La joguina a Catalunya, Barcelona, Edicions 62, 1981, p. I6.

Álvarez, Francisco: «Investigar el juego», Cuadernos de Pedagogía, 99 (1983), p. 16.

Grupo Adarra: En busca del juego perdido, Bilbao, Adarra, I984, p. 5.

Ibídem, p. 29.

«Juegos populares autóctonos y tradicionales». Conselleria de Educación e OrdenaCIÓN UnIVERsitaria: «Decreto 245/1992 de 30 de xullo, polo que se establece o currículo de Educación Primaria na Comunidade Autónoma de Galicia», DOG n. ${ }^{\circ}$ 158, venres I4 agosto 1992. 
EL JUEGO POPULAR Y TRADICIONAL EN LA HISTORIA DE LA EDUCACIÓN ESPAÑOLA CONTEMPORÁNEA

ANDRÉS PAYÀ RICO

Cataluña ${ }^{53}$, País Vasco ${ }^{54}$ o Canariasss, se programa la enseñanza de juegos populares y tradicionales, una inclusión que, en el caso de Andalucía, se argumenta de la siguiente forma: «Debe entenderse la práctica vinculada a la cultura circundante que, en el caso de la Comunidad Andaluza, aporta multitud de tradiciones y manifestaciones propias de indudable riqueza. Conviene por tanto tener en cuenta la importancia de que los alumnos y alumnas conozcan y practiquen juegos autóctonos y tradicionales, como vínculo y parte del patrimonio cultural de nuestra Comunidad» ${ }^{6}$, igualando en importancia a los juegos populares con el patrimonio histórico artístico de carácter monumental u otras tradiciones culturales propias del patrimonio inmaterial autonómico.

El hecho de que, tras muchas décadas, los juegos populares y tradicionales pasen a incorporarse oficialmente al currículo escolar de muchas comunidades autónomas hace que surjan propuestas didácticas para darles acogida en los centros educativos. Al mismo tiempo, los educadores continuarán justificando la pertinencia pedagógica del juego tradicional por tratarse de un buen instrumento de educación social, aprovechando la oportunidad de que «existe un repertorio variadísimo de juegos tradicionales de gran interés educativo por lo que comportan de educación de puntos de vista, aceptación y regulación de normas, aunar esfuerzos, cooperación de unos con otros, etc.»\$7. Una de las profesoras que más estudió la forma de aplicar el juego tradicional motriz es Eugenia Trigo Aza, la cual en 1994 programa esta actividad lúdica en el área de educación física, si bien es consciente de que también es posible (y así lo refleja el currículum de educación primaria) aplicarlo en el área de conocimiento del medio natural, social y cultural; así como en el área de educación artística o cualquier otra. En esta tarea habrá de implicarse todo el profesorado que «tiene el cometido de recuperar el juego autóctono y tradicional. No solamente el profesor de educación física. En las diferentes áreas, se deben desarrollar los aspectos lúdicos de cara a la educación del tiempo libre y el juego tradicional es al mismo tiempo una manera de educar ese tiempo libre» ${ }^{\$ 8}$; todo ello, con la pretensión de conseguir los siguientes objetivos

53 «Juegos tradicionales y populares». Generalitat de Catalunya Departament d’EnsenyaMENT: «Decreto 95/1992, de 28 de abril, por el cual se establece la ordenación curricular de la educación primaria», $D O G C \mathrm{I} 593$, de I3 de maig de 1992.

${ }_{54}$ «Práctica de los juegos populares y tradicionales». PAís VAsco: «Decreto 236/1992 de II de agosto, por el que se establece el currículum de la Educación Primaria para la Comunidad Autónoma del País Vasco», BOPV de jueves 27 de agosto de 1992.

"s «El juego como manifestación social y cultural (juegos populares, autóctonos y tradicionales) [...] Valoración de los juegos populares, autóctonos y tradicionales como vínculo y parte del patrimonio cultural de la comunidad». Consejería de Educación, Cultura y Deportes: «Decreto 46/1993, de 26 de marzo, por el que se establece el currículo de la Educación Primaria, Santa Cruz de Tenerife», $B O C$ n. ${ }^{\circ} 44$ de viernes 9 de abril de 1993.

${ }_{56}$ JunTa de Andalucía: «Decreto/r992 de por el que se establecen las enseñanzas correspondientes a la educación primaria en Andalucía», BOJA n. ${ }^{\circ} 56$, de 20 de junio de 1992.

57 NARGANES, José Claudio: Juego y desarrollo curricular en educación física: orientaciones para la reforma en enseñanza primaria, Sevilla, Wanceulen, 1993, p. Io.

${ }_{58}$ Trigo, Eugenia: Aplicación del juego tradicional en el currículum de educación física (vol. II. Aplicaciones), Barcelona, Paidotribo, 1994, p. 27. 
educativos: generar en el alumno un interés especial por el juego tradicional a partir de su práctica; permitir conocer mejor la cultura propia y por ello valorarla; contribuir a la relación con otras personas de distintas edades, sexo y condición; favorecer la mejora cualitativa del uso del tiempo libre; y encaminar la autoestima hacia lo propio ${ }^{5}$. Esta defensa se fundamenta en una antigua justificación, en la que los juegos tradicionales son parte del patrimonio que hay que recuperar para no perder la propia cultura, pues «estamos invadidos por culturas ajenas y estamos olvidándonos de la propia idiosincrasia» ${ }^{60}$, observando la proliferación de otros juegos de origen extranjero como una intromisión o injerencia extraña.

Finalmente, terminamos este breve recorrido por las teorías y prácticas lúdicas que han abogado en nuestro país por la incorporación del juego popular y tradicional en las aulas, recuperando la propuesta que, en la última década del siglo xx, realizan María de Borja y un grupo de educadoras catalanas de recuperación del patrimonio lúdico, presentando su experiencia en las ludotecas como el espacio ideal de acogida para el juego tradicional, por ser en ellas donde se podrá «retrobar els jocs $\mathrm{i}$ les joguines tradicionals coneixent les variants pròpies de la comarca, adequar-los i potenciar-los com a cultura lúdica popular específica de la zona» ${ }^{6}$. Otra propuesta diferente y más aplicada a un juego popular específico es la del maestro gallego Luis Ramos, que plantea otra alternativa para utilizar los juegos tradicionales en el aula, en este caso mediante la introducción de una unidad didáctica sobre el popular juego del trompo o la peonza. Para poder hacer esta idea efectiva, habrá de superarse previamente un obstáculo pues, «a pesar de este convencimiento, a la hora de plantear en mi programación algún juego popular siempre me encontraba con el mismo problema: cómo introducirlos sin que quedaran convertidos simplemente en materia a estudiar o trabajar (simples ejercicios o habilidades) y que, por tanto, perdieran la frescura y el encanto de todo juego infantil» ${ }^{62}$; con el juego libre en el patio, los concursos, talleres voluntarios y en las sugerencias de los mismos alumnos, encuentra la solución a este dilema, lo cual le permite alcanzar el resultado de «la recuperación de ese patrimonio cultural, esa memoria lúdica colectiva, que son los juegos infantiles, de calle, y el rescate de algo tan importante como el placer de jugar sin más ni más, porque sí... de la que tan necesitados estamos todos, niños y mayores, hoy en día» ${ }^{63}$. Para acabar, baste un ejemplo de principios de siglo xxI, en el que todavía se continúa reclamando la vuelta a los juegos tradicionales de épocas anteriores, considerando que los niños y las niñas de décadas pasadas aún eran «receptores y transmisores de la tradición lúdica de la cultura popular, de esa a la que la escuela siempre ha dado la espalda, pero que para nosotros fue muy importante porque

9 Ídem.

6o Trigo, Eugenia: Aplicación del juego tradicional en el currículum de educación física (vol. I. Bases teóricas), Barcelona, Paidotribo, 1994, p. 447.

${ }^{61}$ Borja, María de; Rajadell, Núria; Rovira, Montserrat y Viladés, María Àngels: Les ludoteques catalanes. Estudi d'una realitat, Barcelona, Universitat de Barcelona, 1995, p. I4I.

62 Ramos, Luis: «Gira, trompo, gira...», Cuadernos de Pedagogía, 243 (1996), p. 24.

${ }_{63}$ Ibidem, p. 26. 
nos enseñó aquello que es imprescindible para el completo y armónico desarrollo humano» ${ }^{64}$; ante esta situación se propone:

que hoy es imprescindible, más que nunca, que la escuela tome en serio su papel de transmisora de cultura y no sólo de saberes enciclopédicos, y que convierta sus patios, sus pistas deportivas, sus espacios libres, en aulas y las aulas en auténticos espacios libres, donde la cultura y el conocimiento se mezclen en una sola diversión [...] El juego tradicional debe invadir la escuela, que tiene que ser un lugar donde los niños puedan recibir la cultura popular, que dadas las circunstancias de hoy en día no pueden recibir de otra manera [...] La finalidad de los juegos tradicionales es carecer de finalidad. El motivo del juego no es ganar, ni siquiera competir. La finalidad del juego es jugar, divertirse, estar con los amigos, vivir aventuras. El juego popular es democrático. Todo juego contiene unas reglas, pero las de los juegos populares no son ni fijas ni estandarizadas, ni las impone nadie ${ }^{65}$.

\section{Algunas reflexiones para seguir pensando lúdicamente desde la historia de la educación}

La lectura y el análisis de los diferentes retazos de nuestra historia de la educación contemporánea que aquí hemos ido recogiendo nos muestran, entre otras cuestiones, una curiosa invariante histórica que aparece recurrentemente a lo largo de más de un siglo en los discursos pedagógicos. Nos estamos refiriendo a cómo, a pesar del alarmismo y la constante preocupación por la posible pérdida o desaparición de los juegos populares y tradicionales, a lo largo de las diferentes generaciones y gracias, entre otras cuestiones, a la labor de recopilación, publicación y uso pedagógico, se ha continuado manteniendo la práctica de este tipo de actividad lúdica socializadora. Sin embargo, sí es cierto que, como aludíamos al inicio de este estudio, las condiciones en las que se puede disfrutar de los juegos populares han ido cambiando (espacios, tiempos, compañeros y materiales de juego) en el último siglo. El avance de la cultura urbana, el desarrollo no sostenible de las ciudades y la escasez de entornos públicos de juego libre son factores que dificultan el poder disponer de espacios adecuados para el juego popular y tradicional. De otro lado, las sobrecargadas jornadas escolares (y extraescolares), el tiempo de ocio asociado al consumismo y los videojuegos sedentarios obstaculizan también la libre disposición de tiempo ${ }^{66}$ dedicado a los juegos populares. Finalmente, las familias con un solo hijo/a, la dificultad para compartir juegos con vecinos o familiares, así como las jornadas laborales de los padres, hacen que sea complicado encontrar otros jugadores con los que practicar estas actividades lúdicas. Parece ser que, una vez más, la escuela puede volver a ser ese lugar donde

4 Cortizas, Anton: «El juego (tradicional) en la escuela», Padres y Maestros, 293 (2005), p. 8. Ibídem, pp. 9-10.

66 Payà, Andrés y Oliver, Diana: «La infancia tiene cada vez menos tiempo para jugar», El País, 27 de julio de 20I8, disponible en https: //elpais.com/elpais/2018/o7/II/mamas_papas/I531309495_2I2620. html. 
encontrar espacio de juego popular (el aula, el patio, los pasillos, etc.), tiempo (el recreo y el horario lectivo) y compañeros (alumnos y profesores), sin caer -y esto es muy importante- en un didactismo o una obsesión pedagogicista, sino, más bien, dar rienda suelta al juego libre tradicional en el que las reglas están consensuadas por los jugadores.

Como hemos podido observar, el uso de los juegos populares y tradicionales en la historia de la educación nos ayuda a conocer y comprender mejor el presente. A pesar de que los cambios provocados por el devenir del tiempo han influido en la utilización ideológica, socializadora, patriótica, racial, adoctrinadora, moral o cívica que se ha hecho de ellos en función del momento histórico en el que se encontraran; el esfuerzo de muchos educadores y el interés de los jugadores al practicarlos han permitido que los juegos populares no hayan desaparecido y sean una constante en la historia lúdico-pedagógica de nuestro país. Desde los primeros institucionistas y educadores preocupados por la renovación pedagógica a finales del siglo xix que pretendían imitar el ejemplo de otros países europeos en la implantación de los juegos populares y tradicionales autóctonos, hasta la normalización curricular autonómica de finales del xx, pasando por los maestros y folkloristas catalanes o el uso patriótico del franquismo de los juegos populares, todos, unos y otros, han ido colaborando en la construcción doctrinal y pedagógica de un discurso que defendía y defiende la pertinencia de los juegos populares y tradicionales como un elemento educativo integral de primer orden. 
